\title{
Factors influencing the articular eminence of the temporomandibular joint (Review)
}

\author{
MARIA JUSTINA ROXANA VÎRLAN ${ }^{1}$, DIANA LORETA PĂUN ${ }^{2}$, \\ ELENA NICOLETA BORDEA ${ }^{3}$, ANGELO PELLEGRINI ${ }^{3}$, ARSENIE DAN SPINNU ${ }^{4}$, \\ ROXANA VICTORIA IVAȘCU ${ }^{5}$, VICTOR NIMIGEAN ${ }^{5}$ and VANDA ROXANA NIMIGEAN ${ }^{1}$
}

\author{
${ }^{1}$ Discipline of Oral Rehabilitation, Faculty of Dental Medicine; ${ }^{2}$ Discipline of Endocrinology, Faculty of Medicine; \\ ${ }^{3}$ Department of Specific Disciplines, Faculty of Midwifery and Nursing; ${ }^{4}$ Discipline of Urology, 'Dr Carol Davila' \\ Central Military Emergency University Hospital, Faculty of Medicine; ${ }^{5}$ Discipline of Anatomy, Faculty of Dental Medicine, \\ 'Carol Davila' University of Medicine and Pharmacy, 020021 Bucharest, Romania
}

Received April 28, 2021; Accepted May 28, 2021

DOI: $10.3892 / \mathrm{etm} .2021 .10518$

\begin{abstract}
The temporomandibular joint (TMJ), the most complex and evolved joint in humans, presents two articular surfaces: the condyle of the mandible and the articular eminence (AE) of the temporal bone. AE is the anterior root of the zygomatic process of the temporal bone and has an anterior and a posterior slope, the latter being also known as the articular surface. AE is utterly important in the biomechanics of the $\mathrm{TMJ}$, as the mandibular condyle slides along the posterior slope of the AE while the mandible moves. The aim of this review was to assess significant factors influencing the inclination of the AE, especially modifications caused by aging, biological sex or edentulism. Studies have reported variations in the angles of the slopes of the AE between medieval and recent human dry skulls, as well as between subjects of different racial origin. Recent articles have emphasized the significant role that tooth loss has on the flattening of the AE. Although some papers have described biological sex or age as factors which could be associated with differences in $\mathrm{AE}$ angulations, edentulism seems to be a significant factor impacting on the inclination of the AE.
\end{abstract}

\section{Contents}

1. Introduction

2. Data collection

3. The inclination of the articular eminence

Correspondence to: Professor Victor Nimigean, Discipline of Anatomy, Faculty of Dental Medicine, 'Carol Davila' University of Medicine and Pharmacy, 37 Dionisie Lupu Street, 020021 Bucharest, Romania

E-mail: victornimigean@yahoo.com

Key words: temporomandibular joint, articular eminence, articular eminence inclination, articular eminence flattening, masticatory biomechanics, edentulism
4. Factors influencing the inclination of the articular eminence

5. Biological sex

6. Age

7. Edentulism

8. Conclusions

\section{Introduction}

The temporomandibular joint (TMJ), the most complex and evolved joint in humans, is defined by the paired joints that connect the mandible to the skull, while its name is derived from the two bones that form the joint: the temporal bone and the mandible. A multitude of human mandibular movements are possible due to the TMJ, adapting the human being to omnivorous eating and making possible a wide variety of physiological functions: chewing, swallowing, speaking and even facial expression (1-3). More specific, the TMJ consists of the condylar process of the mandible penetrating into the mandibular fossa of the temporal bone, while the articular disk lays bilaterally between the fossa and the condyle $(4,5)$.

In terms of function, the TMJ allows maximal free motion (it is a diarthrosis) $(2,6)$, but also permits both hinging and gliding movements of the mandible within the three planes of space (7). Therefore, as the TMJ is considered a bicondylar diarthrosis, the two articular surfaces are represented by the condyle of the mandible and the bony eminence on the temporal bone (the articular tubercle or the articular eminence (AE) of the temporal bone) $(2,6)$.

In terms of morphology, TMJ is a synovial joint as it has synovial cavity filled with synovial fluid (5). The main characteristic which differentiates TMJ from other synovial joints is that the TMJ has joint surfaces covered by dense fibrocartilage instead of hyaline cartilage, the former being considered to heal much better than the latter (8-10).

The AE of the temporal bone is an important anatomical structure in the biomechanics of the TMJ and determines the path and type of condylar-disk complex movement (11-13). $\mathrm{AE}$ is represented by the anterior root of the zygomatic process of the temporal bone; it has a convex shape in relation 
to the sagittal plane and a slightly concave shape in relation to the transverse plane. Two slopes have been described for the AE: the anterior slope (the non-articular slope) and the posterior slope (the articular slope, also known as the articular surface), the latter being covered by fibrocartilage. Of uttermost importance is the fact that the condylar process slides forward and downward along the posterior slope of the AE as the mandible moves anteriorly $(7,13,14)$. The inclination of the path traversed by the condyle in relation to the $\mathrm{AE}$ during a protrusive or a contralateral mandibular movement is known as the condylar path/condylar guidance (15-18). The inclination of the condylar path is considered of paramount importance in the oral rehabilitation of any patient (17), while an analogue of the condylar guidance on a dental articulator is necessary in prosthodontics (18). Therefore, the anatomic slopes of AE are represented in the articulator as the horizontal condylar inclination (19). Widman even described an inverse relationship between the angle of the $\mathrm{AE}$ and the occlusal and mandibular planes and stated that the Frankfort horizontal plane-AE angle may be useful in orthodontic treatment (20). As the inclination of the AE dictates the trajectory of the condyle (13), modifications in the AE angulation might result in biomechanical variations of the TMJ $(7,21)$. The particular morphological patterns encountered at bone levels may predispose to affections or complications (22). Furthermore, quite importantly, the AE is exposed to masticatory loads and forces (23). Thus, the AE reflects the changing mechanical loading environment and it develops/remodels its shape to minimize joint loads (24-29). Recently, the morphology of the AE was also found to be associated with facial profile and related to specific facial types as a survey of cone beam computed tomography (CBCT) examinations on 76 patients determined significantly greater values of the height of the AE in brachycephaly (30). Statistically significant increased AE height was observed in the TMJ of male and female participants with brachycephalic profiles as compared with individuals with dolichocephaly (30).

It is a well-known fact that movements in the TMJ are guided by the shape of bones, muscles, ligaments and dental occlusion. AE is a part of the temporal bone on which the condylar process slides during mandibular movements (13). Therefore, AE determines the path and type of condylar-disk complex movement (11-13). As AE is an important anatomical structure in the biomechanics of the TMJ, influencing the mandibular movements in humans, it is important to assess the factors which generate variations in the morphology of the AE. Different factors have been described in the scientific literature as modifying the angulation of the AE. The aim of this review was to describe significant factors influencing the anatomy of the AE, especially variations caused by aging, biological sex or loss of teeth.

\section{Data collection}

Data gathering was performed on medical literature articles from Clarivate Analytics/ISI Thomson Web of Knowledge and PubMed databases. The following keywords were used: 'articular eminence' and 'temporomandibular joint'. Any type of article, review or experimental study was included in the analysis. Only full text papers written in English were selected.
Some of the references of the initially retrieved articles were further analyzed and added to this research. Published articles on the AE of the TMJ, but also on TMJ morphology or TMJ function were selected. Gathering of data was improved with relevant information from three books on TMJ anatomy, TMJ disorders or dental occlusion. Therefore, the gathered data included a comprehensive collection of scientific papers from 1950 to 2020. Furthermore, observations collected from the scientific literature were supplemented with data obtained through authors' personal research.

\section{The inclination of the articular eminence}

The height of the articular eminence $(\mathrm{AEH})$ and the inclination of the articular eminence (AEI) adjust the pathways of the TMJ condyle-disk complex, leading the way the mandible moves (14,31-37). The inclination of the AE is appreciated in relation to the Frankfort horizontal plane (12) and it influences the path of condylar movement and the degree of rotation of the disk over the condyle $(12,13,33)$.

Examinations on human dried skulls have revealed that the AEI develops rapidly and is almost (90-94\%) completed around 20 years of age (12). The AEI increases by approximately $1^{\circ}(38), 1.2^{\circ}-1.3^{\circ}$ (14) each year, reaching morphological maturity earlier than the mandibular condyle (24). The AEI shows great individual differences and a wide variety of AEI values has been described in the medical literature, ranging between $30^{\circ}$ and $94^{\circ}$ (39).

Naturally, there are small variations between the AEI on the left and on the right sides, but no statistically significant difference has been found between right-left AEI in medieval and contemporary Croatian population (31). Yet, other researchers examining 20th century African-American and European-American dry skulls observed that right-left symmetry of AEI angles was present in only $10 \%$ of the cases (40). In addition, a significant steepness of the right AE slopes compared with the left AE angulations was also observed (40). Therefore, Jasinevicius et al concluded that right-left asymmetry of the AE slope angles should be considered normal (40). In addition, Zabarović et al after assessing the AEI on 137 dry human skulls, concluded that the asymmetry between the right and left joints seems to be almost a rule (39).

\section{Factors influencing the inclination of the articular eminence}

Data from medical literature have shown that AEI seems to be influenced by a variety of factors: sex, facial profile, degenerative bone disease, condyle shape, altered condylar position, increasing functional stress on the dentition $(30,41-44)$. The temporal bone component of the TMJ undergoes a remodelling process throughout the whole life $(43,45)$. Increased angulations of the AE have been found in male patients with brachycephaly (30) or in patients with angled condyles (44). Similarly, decreased values of the AEI were encountered in patients with flat or convex condyle or with two or more bone diseases affecting the condyle (44). Interestingly, Rabelo et al found an association between higher mean values of the AEI (and AEH) and box-shaped eminences (46). 
Studies on human dry skulls have concluded that the values of AEI vary between medieval and recent humans $(11,31)$. Therefore, the mean values of the AEI were statistically significant lower in medieval skulls $(11,31)$ probably as a consequence of the different masticatory loads determined by the medieval eating habits (31). However, in another report on 60 human dry skulls specimens, no statistically significant differences regarding the $\mathrm{AE}$ (AEI and $\mathrm{AEH}$ ) were encountered between medieval and contemporary Croatian populations (1). In addition, another paper reported variations between the African-Americans and European-Americans regarding the angles of the slopes of the AE (47). Thus, statistically significant steeper left central and left medial angles of the AE were encountered in European-American dry skulls of males compared to human dry skulls of males of African-American origin (47).

\section{Biological sex}

Several articles have concluded that the AEI and AEH vary in the TMJ of subjects of different biological sex $(23,30,48-51)$. Thus, in a survey on 105 patients, higher mean values of AEI and AEH were measured on CBCT images of males (48). Similarly, Zabarović et al found significantly steeper AEI in both dentate and edentulous dry skull male specimens (39). Moreover, results of another research group showed greater values of AE angulation in males with brachycephaly (30). Moreover, other observations on AEI have indicated elevated values in males over 60 years of age (44). Furthermore, a recent paper stated that completely edentulous men displayed higher AEI values as compared with completely edentulous female patients (23). However, Unal Erzurumlu and Celenk described no statistically significant difference between the AEI values of dentate females and males (23). Moreover, in a 2016 study, no statistically significant differences regarding AEI and AEH were encountered between medieval and contemporary Croatian populations independent of age and sex (1). Additionally, Jasinevicius et al reported in two studies no differences in AE angulation between the sexes $(47,52)$. Interestingly, there are also studies describing elevated AEI values in males than in females, but the measured differences were not statistically significant $(13,49)$. Thus, Sümbüllü et al determined higher AEI and AEH values in men with or without TMJ dysfunction than in women, but the values did not vary with statistical significance (13). Likewise, Chiang et al presented higher, but not statistically significant higher, values of the AEI in the case of men with unilateral posterior missing teeth as compared to women having the same type of edentulism (49).

\section{Age}

An interesting relationship of the AEI with patient age is discussed in the medical literature. A 2012 analysis of 93 CBCT images concluded that the AEI presents the highest values in young adults between 21 and 30 years of age, consequently decreasing after the age of 31 in patients with no TMJ dysfunction (13). However, a 2017 research found no difference in the mean AEI values of patients from different age groups (44). Furthermore, other evaluations on more than 100 skulls reported also no association between AEI measurements and age (47,52). Interestingly enough, it was also published that there could be a correlation between flattening of the AE and a subject's age (53), but complete edentulism leads to accentuated flattening of the posterior slope of the AE than physiological changes caused by age (53). Plus, a recent paper reported no statistically significant differences in the angulation values of the posterior slope of the AE between participants of different ages which presented maintained occlusal support zones at the time of the study (54). After analyzing 170 orthopantomograms, Oruba et al did not confirm a correlation between AEI and age (54). As no significant AEI modifications were described in older people with at least one occlusal support zone per side, Oruba et al concluded that ageing seems not to influence AEI when occlusal support zones are present (54). Hence, alterations in the morphology of the AE such as flattening of the posterior slope of the AE have been associated more with missing teeth/loss of occlusal support zones than with the physiological processes of ageing in itself, which is normally taking place in the TMJ of older patients $(53,54)$

\section{Edentulism}

Edentulism may cause modifications in the masticatory biomechanics, which may lead consequently to changes in the $\mathrm{AE}(23,32,49,53,54)$. Several research groups described finding reduced AEI values in edentate patients compared to dentate ones $(23,32,49,53,54)$. Recently, an analysis of the effects of edentulism on the TMJ determined lower mean AEI in orthopantomograms of edentulous subjects compared to panoramic radiographs of dentate participants in the study (23). As well, results of another 2020 radiological study indicated a major diminution of AEI in the elderly ( $>60$ years of age) with no dental occlusion (54). Important flattening of the AE was observed in older individuals with loss of all occlusal support zones in contrast to elderly in which at least one occlusal support zone per side was still maintained (54). Similarly, in another study, lower angulations of the AE were reported in completely edentulous patients compared to subjects in which dental occlusion was still present (53). Interestingly, AEI might suffer modifications even when there is a single missing tooth (32). Thus, decreased AEI were measured in patients with unilateral tooth loss than in the non-missing teeth subjects (32). Furthermore, another study analyzing the unilateral missing-tooth effect on the AEI recorded slightly reduced (but not statistically significant reduced) AEI values on the side of unilateral posterior edentulism compared with the side where all the teeth were present $(\mathrm{P}>0.05)$ (49). In addition, Hinton described 'more gently sloped' AE in human skeletal samples with molar loss than in specimens with all molars present (41). Interestingly, Granados wrote about the loss of anterior guidance and of cusp height as factors leading to a 'more shallow' AE or even flat in some patients (55). Moreover, Raustia showed that the position of the glenoid fossa was more anterior in edentulous individuals than in dentate ones and even correlated significantly the modifications with the period of time of edentulousness (43). Yet, Unal Erzurumlu and Celenk in 2020 did not find correlations between duration of edentulousness 
and values of $\mathrm{AE}$ angulation (23). However, there are also few studies that found no statistically significant correlation between tooth loss and flattening of the $\operatorname{AE}(39,40)$. Thus, Zabarović et al in 2000 measured approximatively the same mean AEI values in 59 edentulous dry human skulls and 78 complete dental arches human skull specimens (39) and in a 2006 research no significant variations of AE steepness slope were encountered between dentate and partially edentulous populations (40).

Considering the above presented data and the role of experimental models in scientific research in dental medicine (56-59), we believe that it is necessary to further implement an experimental model of normal TMJ, in relation to which any modification at this level should be evaluated.

\section{Conclusions}

A wide range of factors seem to influence AEI values. Studies have reported variations in the angles of the slopes of the AE between medieval and recent human dry skulls, as well as between subjects of different racial origin. Recent reports have emphasized the significant role that tooth loss has on the flattening of the AE. Although some articles have described biological sex or age of the subjects as factors which could be associated with AEI variations, edentulism seems to be a significant factor impacting AEI values.

\section{Acknowledgements}

Not applicable.

\section{Funding}

No funding was received.

\section{Availability of data and materials}

All information provided in this review is documented by relevant references.

\section{Authors' contributions}

MJRV, VN and VRN drafted the manuscript and contributed to data acquisition and study design. DLP, ENB, AP, ADS and RVI participated in the study design and acquisition of data. MJRV, VN and VRN critically revised the manuscript for intellectual content. All authors read and approved the final version of manuscript for publication.

\section{Ethics approval and consent to participate}

Not applicable.

\section{Patient consent for publication}

Not applicable.

\section{Competing interests}

The authors declare that they have no competing interests.

\section{References}

1. Kranjcic J, Slaus M, Persic S, Vodanovic M and Vojvodic D: Differences in skeletal components of temporomandibular joint of an early medieval and contemporary Croatian population obtained by different methods. Ann Anat 203: 52-58, 2016.

2. Laskin DM, Greene CS and Hylander WL (eds): Temporomandibular disorders. An evidence-based approach to diagnosis and treatment. Quintessence Publishing Co., Inc., Batavia, IL, pp3-5 and 36-37, 2006.

3. Ahmad M and Schiffman EL: Temporomandibular Joint disorders and Orofacial pain. Dent Clin North Am 60: 105-124, 2016.

4. Gauer RL and Semidey MJ: Diagnosis and treatment of temporomandibular disorders. Am Fam Physician 91: 378-386, 2015.

5. Ibi M: Inflammation and temporomandibular Joint derangement. Biol Pharm Bull 42: 538-542, 2019.

6. Bermejo-Fenoll A, Puchades-Orts A, Sanchez del Campo F, Panchon-Ruiz A and Herrera-Lara M: Morphology of the meniscotemporal part of the temporomandibular joint and its biomechanical implications. Acta Anat (Basel) 129: 220-226, 1987.

7. Fan XC, Singh D, Ma LS, Piehslinger E, Huang XF and Rausch-Fan X: Is there an association between temporomandibular disorders and articular eminence inclination? A systematic review. Diagnostics (Basel) 11: 29, 2020.

8. de Bont LG, Liem RS and Boering G: Ultrastructure of the articular cartilage of the mandibular condyle: Aging and degeneration. Oral Surg Oral Med Oral Pathol 60: 631-641, 1985.

9. Robinson PD: Articular cartilage of the temporomandibular joint: Can it regenerate? Ann R Coll Surg Engl 75: 231-236, 1993.

10. Chang CL, Wang DH, Yang MC, Hsu WE and Hsu ML: Functional disorders of thetemporomandibular joints: Internal derangement of the temporomandibular joint. Kaohsiung J Med Sci 34: 223-230, 2018.

11. Kranjčić J, Vojvodić D, Žabarović D, Vodanović M, Komar D and Mehulić K: Differences in Articular-eminence inclination between medieval and contemporary human populations. Arch Oral Biol 57: 1147-1152, 2012.

12. Katsavrias EG: Changes in Articular eminence inclination during the craniofacial growth period. Angle Orthod 72: 258-264, 2002.

13. Sümbüllü MA, Cağlayan F, Akgül HM and Yilmaz AB: Radiological examination of the articular eminence morphology using cone beam CT. Dentomaxillofac Radiol 41: 234-240, 2012.

14. Baqaien MA, Al-Salti FM and Muessig D: Changes in condylar path inclination during maximum protrusion between the ages of 6 and 12 years. J Oral Rehabil 34: 27-33, 2007.

15. Klineberg I and Eckert SE: Functional occlusion in restorative dentistry and prosthodontics. Mosby Ltd., St. Louis, MI, pp63, 2016.

16. Isaacson D: A clinical study of the condyle path. J Prosthet Dent 9: 927-935, 1959.

17. Prasad KD, Shah N and Hegde C: A clinico-radiographic analysis of sagittal condylar guidance determined by protrusive interocclusal registration and panoramic radiographic images in humans. Contemp Clin Dent 3: 383-387, 2012.

18. Gilboa I, Cardash HS, Kaffe I and Gross MD: Condylar guidance: Correlation between articular morphology and panoramic radiographic images in dry human skulls. J Prosthet Dent 99: 477-482, 2008.

19. Venkateshwaran R, Karthigeyan S, Manoharan PS, Konchada J, Ramaswamy $M$ and Bhuminathan: A newer technique to program a semi adjustable articulator. J Pharm Bioallied Sci 6 (Suppl 1): S135-S139, 2014.

20. Widman DJ: Functional and morphologic considerations of the articular eminence. Angle Orthod 58: 221-236, 1988.

21. Isberg A and Westesson PL: Steepness of articular eminence and movement of the condyle and disk in asymptomatic temporomandibular joints. Oral Surg Oral Med Oral Pathol Oral Radiol Endodontol 86: 152-157, 1998.

22. Enache AM, Nimigean VR, Mihaltan F, Didilescu AC, Munteanu I and Nimigean V: Assessment of sagittal and vertical skeletal patterns in Romanian patients with obstructive sleep apnea. Rom J Morphol Embryol 51: 505-508, 2010.

23. Unal Erzurumlu $Z$ and Celenk P: A radiological evaluation of the effects of edentulousness on the temporomandibular joint. J Oral Rehabil 47: 319-324, 2020.

24. Nickel JC, Iwasaki LR, Gonzalez YM, Gallo LM and Yao H: Mechanobehavior and ontogenesis of the temporomandibular joint. J Dent Res 97: 1185-1192, 2018. 
25. de Zee M, Cattaneo PM, Svensson P, Pedersen TK, Melsen B, Rasmussen J and Dalstra M: Prediction of the articular eminence shape in a patient with unilateral hypoplasia of the right mandibular ramus before and after distraction osteogenesis-A simulation study. J Biomech 42: 1049-1053, 2009.

26. Nickel JC, McLachlan KR and Smith DM: A theoretical model of loading and eminence development of the postnatal human temporomandibular joint. J Dent Res 67: 903-910, 1988.

27. Trainor PG, McLachlan KR and McCall WD: Modelling of forces in the human masticatory system with optimization of the angulations of the joint loads. J Biomech 28: 829-843, 1995.

28. Iwasaki LR, Petsche PE, McCall WD Jr, Marx D and Nickel JC: Neuromuscular objectives of the human masticatory apparatus during static biting. Arch Oral Biol 48: 767-777, 2003

29. Iwasaki LR, Crosby MJ, Marx DB, Gonzalez Y, McCall WD Jr, Ohrbach R and Nickel JC: Human temporomandibular joint eminence shape and load minimization. J Dent Res 89: 722-727, 2010.

30. Costa EDD, Peyneau PD, Roque-Torres GD, Freitas DQ, Ramírez-Sotelo LR, Ambrosano GMB and Verner FS: The relationship of articular eminence and mandibular fossa morphology to facial profile and gender determined by cone beam computed tomography. Oral Surg Oral Med Oral Pathol Oral Radiol 128 660-666, 2019.

31. Kranjčić J, Šlaus M, Vodanović M, Peršić S and Vojvodić D: Articular eminence inclination in medieval and contemporary Croatian population. Acta Clin Croat 55: 529-534, 2016.

32. Fang TH, Chiang MT, Hsieh MC, Kung LY and Chiu KC: Effects of unilateral posterior missing-teeth on the temporomandibular joint and the alignment of cervical atlas. PLoS One 15: e0242717, 2020.

33. Pandis N, Karpac J, Trevino R and Williams B: A radiographic study of condyle position at various depths of cut in dry skulls with axially corrected lateral tomograms. Am J Orthodont Dentofac Orthoped 100: 116-122, 1991.

34. O'Ryan F and Epker BN: Temporomandibular joint function and morphology: Observations on the spectra of normalcy. Oral Surg Oral Med Oral Pathol 58: 272-279, 1984.

35. Atkinson WB and Bates RE Jr: The effects of the angle of articular eminence on anterior disk displacement. J Prosthet Dent 49: 554-555, 1983.

36. Okeson JP: Management of temporomandibular disorders and occlusion. 8th edition. Elsevier Inc., St. Louis, MI, pp2-15, 2020.

37. Corbett NE, Devincenzo JP, Huffer RA and Shryock EF: The relation of the condylar path to the articular eminence in mandibular protrusion. Angle Orthod 41: 286-292, 1971.

38. Ricketts RM: Variations of the temporomandibular joint as revealed by cephalometric laminagraphy. Am J Orthod 36: 877-898, 1950 .

39. Zabarović D, Jerolimov V, Carek V, Vojvodić D, Zabarović K and Buković D Jr: The effect of tooth loss on the TM-joint articular eminence inclination. Coll Antropol 24 (Suppl 1): S37-S42, 2000

40. Jasinevicius TR, Pyle MA, Lalumandier JA, Nelson S, Kohrs KJ, Türp JC and Sawyer DR: Asymmetry of the articular eminence in dentate and partially edentulous populations. Cranio 24 85-94, 2006

41. Hinton R: Changes in Articular eminence morphology with dental function. Am J Phys Anthropol 54: 439-455, 1981.

42. Pirttiniemi P, Kantomaa T, Tuominen M and Salo L: Articular disc and eminence modeling after experimental relocation of the glenoid fossa in growing rabbits. J Dent Res 73: 536-543, 1994.

43. Raustia A: Effect of edentulousness on mandibular size and condyle fossa position. J Oral Rehabil 25: 174-179, 1998.

44. Sa SC, Melo SL, Melo DP, Freitas DQ and Campos PS: Relationship between articular eminence inclination and alterations of the mandibular condyle: A CBCT study. Braz Oral Res 31: e25, 2017.
45. Pirttiniemi $\mathrm{P}$ and Kantomaa T: Relation of glenoid fossa morphology to mandibulofacial asymmetry, studied in dry human Lapp skulls. Acta Odontol Scand 50: 235-243, 1992.

46. Rabelo KA, Sousa Melo SL, Torres MGG, Campos PSF, Bento PM and Melo DP: Condyle excursion angle, articular eminence inclination, and temporomandibular joint morphologic relations with disc displacement. J Oral Maxillofac Surg 75: 938. e1-938.e10, 2017.

47. Jasinevicius TR, Pyle MA, Lalumandier JA, Nelson S, Kohrs KJ and Sawyer DR: The angle of the articular eminence in modern dentate African-Americans and European-Americans. Cranio 23: 249-256, 2005.

48. İlgüy D, İlgüy M, Fişekçioğlu E, Dölekoğlu S and Ersan N: Articulareminenceinclination, height, and condylemorphology on cone beam computed tomography. ScientificWorldJournal 2014: 761714, 2014

49. Chiang MT, Li TI, Yeh HW, Su CC, Chiu KC, Chung MP, Huang RY and Shieh YS: Evaluation of missing-tooth effect on articular eminence inclination of temporomandibular joint. J Dent Sci 10: 383-387, 2015.

50. Magnusson $\mathrm{C}$, Nilsson $\mathrm{M}$ and Magnusson T: Degenerative changes of the temporomandibular joint. Relationship to ethnicity, sex and occlusal supporting zones based on a skull material. Acta Odontol Scand 70: 207-212, 2012.

51. Magnusson C, Nilsson M and Magnusson T: Degenerative changes in human temporomandibular joints in relation to occlusal support. Acta Odontol Scand 68: 305-311, 2010.

52. Jasinevicius TR, Pyle MA, Nelson S, Lalumandier JA, Kohrs KJ and Sawyer DR: Relationship of degenerative changes of the temporomandibular joint (TMJ) with the angle of eminentia. J Oral Rehabil 33: 638-645, 2006.

53. Csadó K, Márton K and Kivovics P: Anatomical changes in the structure of the temporomandibular joint caused by complete edentulousness. Gerodontology 29: 111-116, 2012.

54. Oruba Z, Malisz P, Sendek J, Aardal VE, Kopycińska N, Krzystyniak K, Darczuk D and Kaczmarzyk T: Flattening of the articular eminence is associated with the loss of occlusal support: Radiological study. Aust Dent J 65: 53-57, 2020.

55. Granados J: The influence of the loss of teeth and attrition on the articular eminence. J Prosthet Dent 42: 78-85, 1979.

56. Poll A, Minculescu CA, Nimigean VR, Bădiță D, Bălăceanu RA, Păun DL, Moraru SA and Nimigean V: Experimental model for the study of autogenous mandibular bone grafts integration. Rom Biotechnol Lett 23: 13681-13689, 2018.

57. Nimigean V, Poll A, Nimigean VR, Moraru SA, Badita DG and Paun DL: The routine and specialised staining for the histologic evaluation of autogenous mandibular bone grafts. An experimental study. Rev Chim (Bucharest) 69: 1106-1109, 2018.

58. Poll A, Nimigean VR, Bădiță D, Bălăceanu RA, Cismas SC, Perlea P, Moraru SA and Nimigean V: In vivo experimental model for the evaluation of dental implant integration. Rom Biotechnol Lett 23: 13505-13510, 2018.

59. Nimigean V, Poll A, Minculescu CA, Nimigean VR, Moraru SA, Vîrlan MJR, Bălăceanu RA and Păun DL: Immunohistochemical evaluation of autogenous mandibular bone grafts integration: An experimental study. Rom Biotech Lett 24: 229-235, 2019.

This work is licensed under a Creative Commons Attribution-NonCommercial-NoDerivatives 4.0 International (CC BY-NC-ND 4.0) License. 